Article

\title{
Transparency as a Driver for Logistical Efficiency in WEEE Collection and Transport
}

\author{
Eirill Bø ${ }^{1, *,+}$ and John Baxter ${ }^{2,+}$ (i) \\ 1 Department of Accounting Auditing and Business Analytics, BI Norwegian Business School, Nydalsveien 37, \\ 0484 Oslo, Norway \\ 2 Norwegian Institute for Sustainability Research, Stadion 4, 1671 Kråkerøy, Norway; john@norsus.no \\ * Correspondence: eirill.bo@bi.no \\ + Authors contributed equally.
}

Received: 4 May 2020; Accepted: 24 June 2020; Published: 2 July 2020

\begin{abstract}
Inefficiency in complex reverse-logistical operations, such as the collection and transport of various wastes, can often be traced to two related factors. Adversarial and arms-length relationships between service providers and customers are commonplace, alongside surprisingly limited understanding of the cost base. This study investigated transparency and shared understanding as drivers for higher efficiency and lower costs. Observation and intervention in contractual negotiations was combined with analyses of cost and sensitivity, and a post-contractual transparency exercise with bidders where findings were shared with all parties. The work yielded both immediate efficiency gains and a longer-term infrastructure for cost evaluation and negotiation. Ongoing work is extending the approach into yet more complex and broader areas of municipal waste management.
\end{abstract}

Keywords: WEEE; logistics; efficiency; costing; transparency; relationships

\section{Introduction}

The difficulty of conducting complex reverse-logistical operations in an efficient and sustainable fashion is well-documented. Two recent high-profile examples in the Norwegian context concerned the separate bankruptcies of contractors responsible for municipal waste collection in Oslo and in many other municipalities [1,2]. There were numerous complicating factors in both cases including illegal breaching of workplace environment legislation in one. However, failings in both cases can be traced to basic common causes. In each case, the contractor had made tender offers far too low for the work to be economically sustainable, and there must have been questionable due diligence on the customers' part in accepting such offers.

Both these factors reflect a lack of understanding of costs. Such "blind" operation is very typical of adversarial, arms-length relationships between the two parties, which are traditional for this type of negotiation. Mis-appreciation of the cost base is readily identified; however, cost analysis is far from straightforward. Later work focusing on the Oslo municipal waste operation [3] illustrates the difficulty and complexity in establishing that operational plans in Oslo followed legal requirements. Detailed consideration of the worker salary part of the cost base would have required at least this depth of analysis. Similarly, the analytical part of our own work [4], which we address in the present paper, reveals a fairly complex structure for determining costs.

The two cases listed above were extreme examples resulting in catastrophic failures. We have direct previous experience of more mundane situations with similar features, in a detailed costing exercise for grocery transport logistics [5]. The parties showed keen interest and awareness in certain cost drivers (such as fuel price), yet apparent ignorance/disinterest with respect to others (particularly wage costs). The level of interest seemed to be driven by the obviousness of the data more than 
the importance of a particular cost driver. The present study arose from our observation of similar conditions in the context of WEEE (waste electrical and electronic equipment) transport.

Our experience and the research evidence indicate that such operations-highly sub-optimal and with borderline financial sustainability at best-are commonplace. These operations are obviously highly vulnerable and developing strategies to tackle the issues would be very useful. Application of such strategies could have wide-ranging effects across the (reverse-) logistics sector. The study's main aim is to show that supplier-consumer relationships in waste transport logistics are under-researched and under-appreciated. Common practice in cost estimation and contractual interaction between parties is often vague-heuristic- and experience-based. The study's distinctive element relates to analysis of supplier-consumer interactions through the lens of principal-agent theory. The study shows that "technical" understanding of cost and logistical efficiency drivers is necessary but not sufficient to drive real improvements; positive relationships based on transparent information-sharing are also crucial. The case-study approach means that the outcomes are necessarily somewhat localised, but some general conclusions across different sectors and localities can be drawn.

The paper describes an approach to tackling these issues in the context of WEEE and considers the implications in ongoing work for municipal waste management. The remainder of this paper is structured as follows. We explore the relevant theoretical background and how it can be deployed in practice. Then, we describe our specific approach to this research, followed by the principal findings and a discussion thereof. We draw conclusions which show how the findings might be further developed and widened in other areas of operation.

\section{Relevant Research}

Operational complexity in the reverse-logistical sector is well-documented. Wide ranging reviews of municipal solid waste collection [6] and WEEE [7] are testament to the depth and complexity of the issues. These include network design, collection planning, vehicle routeing and decision-making amongst a host of other factors. In the context of WEEE, there are essentially two strands of this work. The first concerns the design of networks-this relates to the placing of facilities to optimise the flow of materials (in this case, WEEE) through the network. Examples include attempts to design national WEEE networks essentially from scratch, as in Portugal [8] or Turkey [9,10]. Regional or local (e.g., city-based) networks can also be developed on this basis. This type of research is of limited relevance in areas such as Norway, in which the WEEE transport infrastructure is already firmly established (the collection points, intermediate and final treatment locations are essentially fixed). In this case, the issue shifts to how WEEE is transported through the network-the movements of carrier vehicles such as trucks, trains or boats, come into primary focus. Vehicle routeing and route planning are the watchwords for this type of research. A clear example of modelling a regional network in an Italian context [11] has been illustrated.

However, little of this work appears to be practically applicable in improving reverse-logistical operations. In part, this can be ascribed to the relative scarcity of research into non-operational factors relating to finance, organisation or the relationships between actors. One example [12] shows how changes to the financing model for WEEE collection and recycling under the umbrella of extended producer responsibility could drive greater efficiency and sustainability. However, even this work remains somewhat abstract and not obviously connected to practical experience of relevant actors. Our previous work in this area [4] highlights issues relating to the inter-relationship between logistical efficiency and costs and describes an economic model for WEEE collection costs.

The present study illustrates the practical use of this model, loosely based on previous work on traditional forward logistics within the retail grocery sector $[5,13]$. This work showed the importance of the perceptions of the suppliers and providers of reverse-logistical services. The study described a detailed costing exercise and the associated data-gathering. Parties showed keen interest and awareness in certain cost drivers such as fuel price, yet apparent ignorance or disinterest with respect to others, particularly wage costs. However, the level of interest seemed to be driven by the obviousness and 
transparency of data, more than concern for the importance of a particular cost driver. This explains the relative blindness of many actors towards cost as previously noted. The overall cost base is a complex entity and many of the factors are, or seem, intractable. Hence costs are at least partly evaluated according to "experience", which in practice may amount to little more than guesswork.

The second major strand of relevant research concerns the relationship and negotiations between the relevant actors. Both the previous and present studies are based on outsourced logistical services. A traditional view of negotiation and contract-making $[5,14]$ is that the final price arises from a negotiated "truce", following a battle between the conflicting self-interests of the two parties. Whilst trends in supply chain management suggest that increasing cooperation between supply chain partners is increasingly preferred to such arms-length, even adversarial, relationships of old [15-17], the adversarial model [18] is still identified as dominant. It implies, amongst other factors: information exchange between parties being limited to the essentials of doing business, short-term relationships, and self-interested strategies. A game-theoretical construct similar to the Prisoner's Dilemma is also used [18] to show that transition to a more collaborative relationship must be undertaken by both parties simultaneously; unilateral action would cause the collaborating party to be exploited by the other. In turn, this essentially obligates external intervention.

It is easy to show that "battle and truce" may not lead to optimal results for either party. A "win" for the supplier, taking this to mean securing the highest short-term headline price as possible, may compromise the length or stability of the contractual arrangement, inhibit the development of trust and cooperation, and so on. The short-term nature of contracts is known to be a significant inhibitor of investment and innovation in closely related operations such as plastics recovery in WEEE recycling [19]. Higher prices may also be counterproductive in that they could permit higher costs and incentivise objectively less efficient operations. This might be in the interest of suppliers but not of purchasers nor of the overall value chain in an objective sense. On the other hand, a comprehensive "victory" for the purchaser could result in prices that are objectively too low, failing to reflect the true operational difficulty and cost. This may result in the agent losing money and ultimately being unable to continue in what should have been an objectively sustainable and efficient operation. This was seen with catastrophic consequences in the Norwegian municipal waste collection failures outlined above [1,2].

Principal-agent theory [20] provides a framework for exploring elements of these relationships. The interests of the principal (i.e., the purchaser) and the agent (the supplier) are not perfectly aligned, and each is expected to act in their own self-interest. This is the principal-agent problem, often framed from the principal's perspective-meaning it concerns the agent's potential to act in their own interests and against those of the principal. A cornerstone of the agency problem is that part of the agent's knowledge and behaviour is invisible to the principal (and, in general, vice versa). The theory effectively assumes the "battle and truce" model of negotiation, whereby the interests of different parties are assumed to be non-aligned and more or less in direct competition.

Two distinct aspects of the agency problem arise-adverse selection refers to (unverifiable) misrepresentations made by the agent in the process of reaching agreement with the principal. Classically this refers to statements regarding the agent's ability or competence, but more generally refers to anything in the agent's interests. The over-statement of costs and a consequently inflated price proposal is perhaps the simplest imaginable, yet probably most prevalent, example of adverse selection. It is specifically an example of pre-contractual opportunism [21], which stems from information asymmetry, where one party has access to information that is hidden from the other. The classical formulation of the problem has asymmetry in favour of the agent-hence the unverifiability of their claims-but elements of asymmetry could also be in the principal's favour. The second aspect of the classical agency problem is moral hazard-which is usually technically defined in terms of risk and responsibility, but here refers to (unverifiable or invisible) behaviour of the agent that is contrary to the agreement. It is often framed as "shirking" but is arguably more general-it refers to any action (or lack thereof) that is in the agent's interests but not those of the principal. The present study mostly concerns 
contractual and negotiation processes, so adverse selection is mostly in focus, although elements of moral hazard are also observed.

Agency theory provides several suggested mechanisms by which the principal may address the agency problem. In longer-term relationships, trust developed between the partners may reduce the tendency towards agency problems. However, two other inter-related elements are more common and more generally applicable-information and contract-making. The former, put simply, suggests that if the principal can be sufficiently well-informed of what the agent is doing, then the agency problem is essentially eliminated. However, it seems logical that whilst this may be a quite effective defence against moral hazard (which focuses upon what the agent does or does not do), it may be less so against adverse selection-information in this context normally refers to post-contractual information on the agent's actions. More generally, the need for information flows in both directions between the parties has been highlighted [22], with principals clearly stating performance criteria and relevant metrics, and agents making the relevant information available for real-time monitoring. The theory establishes two distinct types of contractual arrangements between principals and agents [23]. A behavioural-based contract rewards the agent based on what they do-their behaviour-rather than what results from that behaviour. In contrast, an outcome-based contract means the agent is rewarded on results. The essential difference between these types of contracts in classical agency theory relates to risk and how it is shared between actors. Risk, in this context, arises because outcomes depend partly on factors that are outside the actors' control (specifically, outside the control of the agent). Where contracts are outcome-based, such risk is transferred to the agent, since their reward is not entirely connected with their behaviour. In contrast, behavioural-based contracts mean that the agent is rewarded if they act appropriately, no matter what the outcome-and hence the risk related to the uncontrollable factors falls on the principal. It follows that outcome-based contracts are a general means by which the principal can insulate themselves from opportunistic behaviour, and specifically moral hazard. However, it is far less obvious how outcome-based contracts protect against adverse selection and price-setting.

In the WEEE transport context, typical risks relate to uncertainty and fluctuation in the volumes of waste to be collected from given localities over given time-frames, in customer expectations and behaviour-for example, the frequency with which collection is expected/demanded, and in operational cost factors-for example, relating to fluctuations in the price of fuel, labour or other elements of variable cost. One simple way in which principals manage their exposure to risk is to offer contracts on a relatively short-term basis; this is typical of the sector. However, as mentioned above, this has been shown to negatively affect investment and innovation and ultimately this seems likely to inhibit cost-efficiency in the longer term. Different types of contracts have been identified in the specific context of waste transport provision. The essential nature of the contract is manifest in the pricing format. For example, pricing per trip would be typical in a behaviour-based contract, whereas pricing per mass of waste collected and delivered would be indicative of an outcome basis. They suggested the possibility of a collaborative contract that lies in-between the behavioural and outcome-based extremes. This is based upon flexible pricing, based upon true cost with trust between actors also playing an important part. They also referred to risk-sharing and the need for information, noting that behavioural-based contracts generally require the principal to be relatively well-informed, whereas outcome-based contracts shift the requirement for information away from the principal and towards the agent.

In summary, without external intervention both to inform the parties on cost structures and sensitivities, and to monitor and steer the interaction between them, sub-optimal outcomes to the purchasing and supply of WEEE transport logistics seem rather likely. The study established a managed intervention process to improve these outcomes.

\section{Materials and Methods}

The work described here was part of a broader study of WEEE transport logistics, involving one principal and a number of agents. The principal was Elretur AS, since renamed Norsirk AS-a producer responsibility organisation (PRO), which is a membership organisation for electronics producers to 
discharge their responsibilities under extended producer responsibility. PROs generally do not engage directly in transport and recycling, instead adopting a co-ordinating role and contracting out the transport work to specialist carriers (the agents here). Elretur/Norsirk is one of the largest PROs in Norway with about $30 \%$ of the national WEEE market, focusing mostly on household rather than commercial WEEE.

Our work consisted of the following stages:

- We interviewed key personnel from the principal and from their legal representatives. We questioned the principal regarding their understanding of the cost base and the sensitivity of the cost to important drivers. Most specifically, we explored issues of (dis)economies of scale and how unit costs could vary with collected volume. This was also a key feature of discussions with legal representatives, which focused on issues relating to contractual structure and penalty or bonus clauses where volumes collected varied from those agreed.

- We interviewed the (candidate) agents similarly about their understanding of the cost base and cost sensitivities. We invited them to provide "transparency data" on important cost factors.

- Using our own logistical and costing models (described in detail in [4]), we calculated the true costs and sensitivities to key factors for a particular WEEE collection and transport duty across the municipality of Oslo.

- We observed the arrival and unloading of transport vehicles at WEEE reception facilities and were able to interview the drivers of these vehicles. The vehicles seen were completely full of WEEE; drivers told us that they collected until the vehicle was completely full on each trip. They reported collecting both on behalf of Elretur and of other PROs at the same time. They claimed to be able to distinguish waste collected on behalf of different actors, although this seemed impossible to discern by superficial inspection.

- We presented our findings to principal and agents alike within the contractual negotiation process. Importantly, the awarding of contracts was not directly contingent on our work. The idea was to give both parties a much better and detailed appreciation of their own cost breakdown, with a view to more informed negotiation in subsequent contractual rounds.

The aims of the work were:

- To gauge the understanding of principals and agents alike to the true costs, the efficiency of operations and the factors affecting these;

- To examine the process of principal-agent theory (to see if common principal-agent problems were in play);

- To share these findings transparently with both principal and agents, in the belief that such information-sharing would eventually improve efficiency and drive down costs.

The costing model was developed throughout 2013 with the contractual processes taking place over the winter of 2013/14. The broad approach for assessing cost and arriving at contractual agreements remains in place to this day. The study is partly based on an action research approach [24], which has a broad recent history in logistics [25-27]. The approach allows researchers to participate in practical problem solving and to observe the effects of their work. The goals are to learn about a specific problem, develop in-depth understanding of it and generate new knowledge [28-30]. Such a practical problem-solving approach enables the researcher to undertake empirical confirmation of the consequences of changes in practice. In this project, action research methodology was used to link theory and practice regarding transportation price and costing.

\subsection{Estimation of Costs Using Transport-Logistical and Economic Models}

The study here concerns collection and transport of WEEE in the Oslo region. The focus is a relatively simple operation involving the transfer of WEEE from 23 collection points to a single delivery point outside the region itself, as shown in Figure 1. Over the year, around 3300 tonnes of WEEE were 
transported. The collection points varied in size and scope. Nearly $80 \%$ of the total mass collected came from the four highest-volume sites; these were visited on at least a weekly basis. Most other sites were visited 1-2 times per month. Across all sites, most collections ranged from a few hundred kilograms up to several tonnes in mass, with some of the higher-volume sites having larger collections (up to 20 tonnes) from time to time.

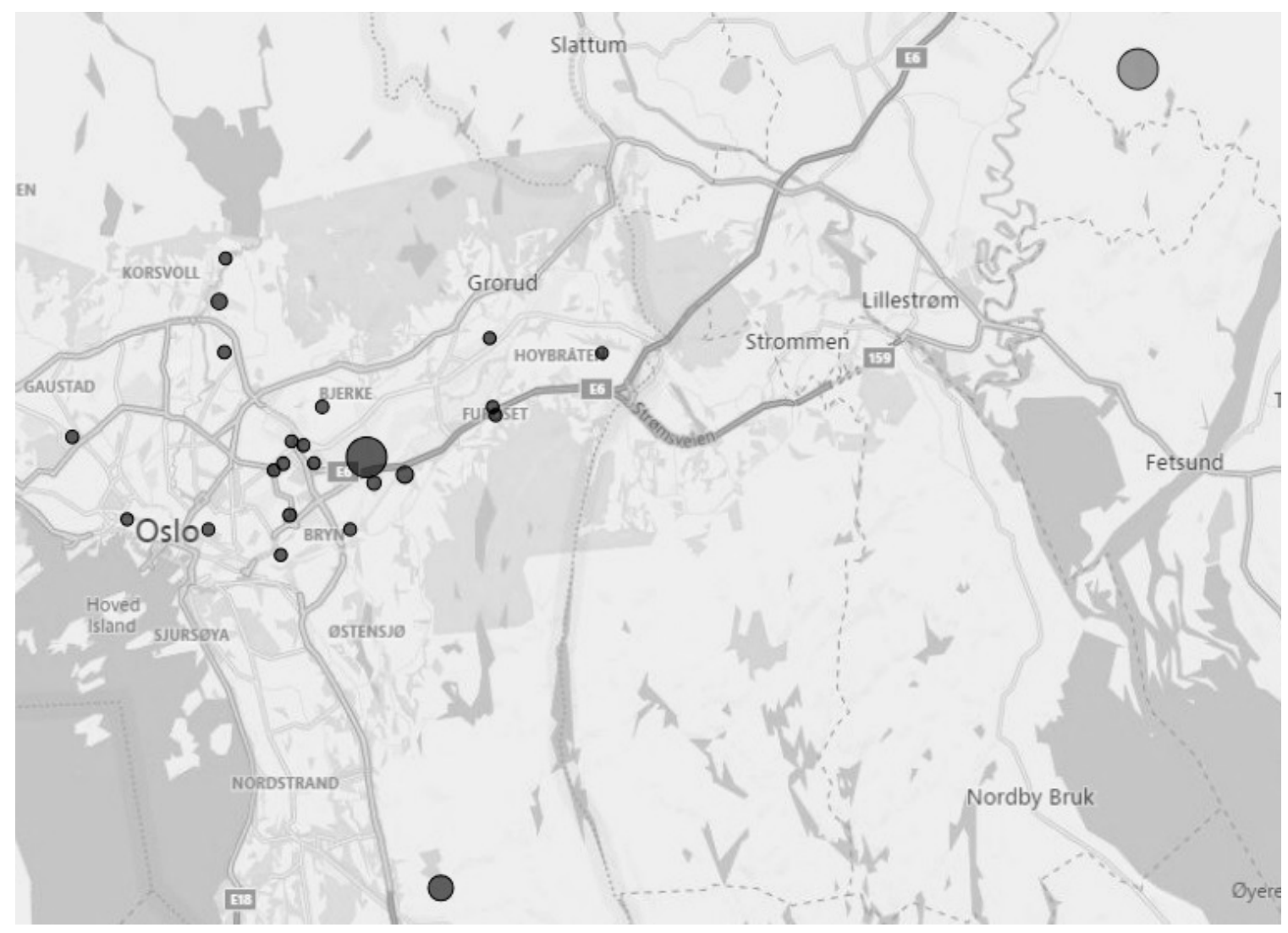

Figure 1. Location of collection and delivery points across the Oslo region. The delivery point is the separate location to the north-east. The points scale with the mass of waste collected/delivered.

As described previously [4], the required driving distance for trucks of a specific capacity (in this case, 17 tonnes net) to complete the annual collection/delivery duty was calculated as a reverse-logistical vehicle routeing problem in the ArcGIS software environment. The distance driven should be a function of service level-meaning the extent to which WEEE is collected on-demand at the customer's convenience, as opposed to when it is most efficient for the transporter. However, the previous work [4] established that actual transport work does not vary greatly with service level for urban environments with relatively densely clustered collection points. For simplicity, the calculations here assumed "minimum service" meaning maximum efficiency for the transporter. This is a relatively safe assumption here; it would be much less so in rural locations with collection points tens or even hundreds of kilometres apart. The total transport duty was found to be $14,465 \mathrm{~km}$. This is a key parameter in the calculation of costs (also see [4]). Costs are expressed in three categories:

- Fixed costs (independent of driven distance)—depreciation of capital equipment, such as trucks and trailers, cost of capital, also insurance, administration and taxes;

- Variable costs (directly dependent on driven distance)—fuel, maintenance and tyre replacement, all expressed directly per driven kilometre;

- Salary costs (indirectly dependent on driven distance)—depends on the total operational time of the vehicle in hours and the average hourly staff rate. 
We calculated the best estimate of true costs for this transport duty and the sensitivities to that estimate; the findings are given below.

\subsection{Transparency Exercise with Agents}

Following the award of contracts, bidders (both successful and unsuccessful) were invited to submit their own estimates for various cost factors, specifically:

- Administration cost per year;

- Insurance cost per year;

- Fuel economy (diesel usage in litres/10 km);

- Average maintenance cost per km;

- $\quad$ Average tyre replacement cost per km;

- $\quad$ Average price of diesel per litre;

- $\quad$ Average staff salary per hour.

The other cost drivers-most importantly, capital depreciation and cost of capital—were taken as identical for all bidders; this was deemed the fairest assumption. Table 1 shows the transparency data. All costs are in Norwegian kroner.

Table 1. Agent estimates of cost factors for the Oslo region waste electrical and electronic equipment (WEEE) collection duty.

\begin{tabular}{ccccccc}
\hline & Offer 1 & Offer 2 & Offer 3 & Offer 4 & Offer 5 & Offer 6 \\
\hline Administration per year & 95,667 & 30,000 & 180,000 & 75,000 & 250,000 & 180,000 \\
Insurance per year & 30,009 & 30,000 & 40,000 & 32,000 & 30,000 & 40,000 \\
Diesel use per 10 km & 4.00 & 4.00 & 5.10 & 5.50 & 5.50 & 5.10 \\
Maintenance per km & 3.84 & 1.00 & 2.40 & 1.50 & 0.80 & 2.40 \\
Tyres per km & 1.16 & 1.00 & 0.80 & 1.00 & 0.50 & 0.80 \\
Diesel price per litre & 10.40 & 12.00 & 9.60 & 9.88 & 13.00 & 9.60 \\
Staff salary per hour & 228.50 & 180.00 & 270.00 & 200.00 & 250.00 & 270.00 \\
\hline
\end{tabular}

The implications of these estimates are explored below.

\section{Results and Discussion}

Our work in this project-before, during and after the contract negotiation phase-enabled us to build-up a comprehensive picture of the process. Prior to intervention, the following features of the system were observed.

- All parties (principals and agents alike) were acting "blind" in many respects, with serious limitations in their understanding of the true cost base and the true logistical efficiency for WEEE transport.

- $\quad$ All contracts were essentially outcome-based; pricing was inevitably per unit mass.

- The interaction was largely adversarial, i.e., "battle and truce" was a reasonable description of the negotiation processes.

- In the language of principal-agent theory, the behaviour of agents was consistent with adverse selection and pre-contractual opportunism.

\subsection{Observations and Interviews}

Discussions with the principal prior to the project made it very clear that they were relatively blind regarding cost and logistical efficiency. They had not directly considered any of the factors in the costing model at all, instead implicitly relying on the idea that market forces would lead to an optimal contract. The agents stated directly that they had based their pricing on "long experience" rather than a scientific cost breakdown. The transparency results are discussed further below, but they show 
reasonable consistency across bidders for some factors but marked differences for others. Especially in the latter case, it appears that factors may not have been considered in any detail at all. Initial reactions to the detailed cost model regarded it as "just theory" and "nothing to do with the real world". All these findings mirror the experience of previous studies [5] and reinforce the notion of blindness on the part of both parties. The principal hoped they were getting a reasonable deal; agents believed they were offering a good deal for themselves but did not understand why in any depth.

Risk seemed not particularly well-understood by either party and was managed crudely, the principal doing so via only offering short-term contracts and the agents apparently doing so via "conservative" over-pricing. The lack of detailed knowledge about risk from both parties became clear in the early stages of developing the detailed costing model, prior to any specific interventions. One specific example came via accounts of historical contract negotiations between the principal and a number of agents (private communication). These were nominally outcome-based contracts, priced per unit mass of waste transported. The main risk factor explicitly considered was the potential fluctuation in available volume of WEEE to be transported. Specific pricing structures were introduced such that if the volume of WEEE fell, the price paid per unit mass collected would rise, by up to $15 \%$. However, from what we now know, neither party could have known much at the time about the true effect of fluctuating volume on collection and transport cost per unit mass. Later calculations using the detailed costing model and extensive data for a much more comprehensive assessment [4] showed that the price-sensitivity was roughly correct; the true cost across the range considered varied by about $20 \%$. However, it is clear that the pricing structure at the time was arrived at largely by instinct.

Compelling evidence of adverse selection and pre-contractual opportunism arose during the negotiation process with the eventually successful bidder. As part of this, we presented the detailed cost analysis to both parties. It represented a much more comprehensive analysis than had been seen previously, although there were considerable uncertainties in the underlying data; these were rectified somewhat at a later stage. At the time, many elements were difficult to measure or estimate, and/or deemed to be proprietary information. Nonetheless, the immediate result was a rapid and drastic over-the-table reduction in offer price by the agent. The inevitable conclusion is that this suggests there was adverse selection, specifically the "conservative" setting of an initial offer price well above the range they would ultimately be prepared to accept. The reduction was much too great to be explained as a shift within a margin range. As mentioned above, the agent stated directly that the initial offer price was not calculated particularly scientifically, more that it was "based on long experience". Moreover, there was little effort (from either party) to challenge or critically analyse the cost breakdown.

It eventually became clear that the biggest specific source of adverse selection was in the lack of transparency regarding agents' relationships with competing PROs. Pricing and costing were structured as if the carrier had an exclusive relationship with each PRO, whereas in practice they were agents for several PROs simultaneously. Thus, the PROs were subject to diseconomies of scale in the price they paid, whereas the carrier could reduce these in consolidating their operations across numerous PROs-also, the vehicles and staff may also have been engaged in non-WEEE related work. The detailed costing model showed this to be arguably the most important factor for true cost and hence "fair" price [4]. It is arguable that the "over-pricing" was reflective of a reasonable risk management strategy on the part of the carriers, and this was not contractually disallowed. Nonetheless, it became clear that much more transparent relationships across the board could help both carriers and PROs in the management of risk and the delivery of lower prices.

\subsection{Cost Calculations and Sensitivity Analysis; Evaluation of Transparency Data}

The details of the cost calculation can be found in [4] and are only briefly summarised here. The fixed cost is the sum of three factors-the average annual depreciation of capital equipment (meaning vehicles), the average annual cost of capital and other fixed cost elements (insurance, administration and taxes). Variable costs consist of fuel, maintenance and tyre replacement, all expressed per unit distance driven. Finally, salary costs are based on average hourly staff rates and the total operational 
time of the vehicles, which in turn depends on distance driven, time taken, number of stops and loading/unloading times. All of these factors are independently variable and the sensitivity to many different factors can be assessed.

The previous study focused mostly on the differences between urban and rural areas; here, we focus more closely on the costs for the Oslo region and related sensitivity analysis. Some changes to the approach for cost allocation were made from the previous study to achieve fairer comparisons with the tenders. The cost allocations for fixed cost elements, such as capital depreciation and insurance, were adjusted to reflect the reality that the inner city and outer suburbs were served by vehicles of different sizes.

The overall task across Oslo was the collection of 3311 tonnes of WEEE from 23 different sites, covering a total of 14,465 driven kilometres, making a total of 492 separate collections with an estimated total working time of $1853 \mathrm{~h}$. These data combined with our impartial assessment of the various cost parameters, based in part on extensive field observations of the operation [31], is shown in the first column of Table 2 and gives a total cost estimate of around 925,000 NOK or 280 NOK per tonne. Based on agents' own transparency data from Table 1, their estimated costs for optimal operation were in the broad range of our impartial assessment, in the range 200-300 NOK per tonne, as shown in Table 2.

Table 2. Estimated cost per tonne for WEEE collection from our economic costing model, based on the supplied transparency data as given in Table 1.

\begin{tabular}{cccccccc}
\hline & Indep & Offer $\mathbf{1}$ & Offer $\mathbf{2}$ & Offer $\mathbf{3}$ & Offer $\mathbf{4}$ & Offer $\mathbf{5}$ & Offer $\mathbf{6}$ \\
\hline Depreciation & 44 & 44 & 44 & 44 & 44 & 44 & 44 \\
Cost of capital & 8 & 8 & 8 & 8 & 8 & 8 & 8 \\
Insurance & 8 & 9 & 9 & 12 & 10 & 9 & 12 \\
Administration & 30 & 29 & 9 & 54 & 23 & 76 & 54 \\
Tolls & 1 & 1 & 1 & 1 & 1 & 1 & 1 \\
Total Fixed Costs & $\mathbf{9 1}$ & $\mathbf{9 1}$ & $\mathbf{7 1}$ & $\mathbf{1 1 9}$ & $\mathbf{8 5}$ & $\mathbf{1 3 8}$ & $\mathbf{1 1 9}$ \\
\hline Diesel & 13 & 18 & 21 & 21 & 24 & 31 & 21 \\
Maintenance & 4 & 17 & 4 & 10 & 7 & 3 & 10 \\
Tyres & 4 & 5 & 4 & 3 & 4 & 2 & 3 \\
Total Variable Costs & $\mathbf{2 1}$ & $\mathbf{4 0}$ & $\mathbf{3 0}$ & $\mathbf{3 5}$ & $\mathbf{3 5}$ & $\mathbf{3 7}$ & $\mathbf{3 5}$ \\
\hline Salary: driving & 26 & 20 & 16 & 24 & 17 & 22 & 24 \\
Salary: stops & 7 & 5 & 4 & 6 & 4 & 6 & 6 \\
Salary: loading & 93 & 70 & 56 & 83 & 62 & 77 & 83 \\
Salary: unloading & 43 & 32 & 26 & 38 & 28 & 35 & 38 \\
Total salary costs & $\mathbf{1 6 8}$ & $\mathbf{1 2 8}$ & $\mathbf{1 0 1}$ & $\mathbf{1 5 1}$ & $\mathbf{1 1 2}$ & $\mathbf{1 4 0}$ & $\mathbf{1 5 1}$ \\
Overall total costs & $\mathbf{2 8 0}$ & $\mathbf{2 5 9}$ & $\mathbf{2 0 2}$ & $\mathbf{3 0 6}$ & $\mathbf{2 3 2}$ & $\mathbf{3 1 4}$ & $\mathbf{3 0 6}$ \\
\hline$\quad$ 1 This is our independent assessment of the costs based on the data available. &
\end{tabular}

Fixed costs accounted for around $30-40 \%$ of the total across the range of data supplied. The most important variable by far of the ones included in the transparency exercise was "administration"; this varied greatly and was particularly high for some of the offers, representing over half the total fixed cost. In practice it seems likely that capital depreciation (not allowed as a variable in the transparency exercise) is a very important factor also. Variable cost estimates differed across the offers perhaps more than would be expected, but in any case, were the least important category, representing $10-15 \%$ of total cost. Salary costs were the biggest factor of all ( $45-60 \%$ of the total) and varied quite significantly across the offer range. It seems clear that this is the most readily controllable cost category, although the cases mentioned in Section 1 with dubiously legal working conditions showed what can happen if personnel cost control is taken too far.

Most important of all, however, is how these cost estimates compared with the actual tenders made, prior to the transparency exercise. Initial tender offers for the work ranged upwards from 1.9 million NOK, corresponding to around 600 NOK per tonne. Even taking the most pessimistic estimates across all the transparency data gives a cost of only around 350 NOK per tonne. It is therefore 
clear that the agents were at least engaging in conservative over-pricing, if not outright adverse selection. As mentioned above, these tenders were "based on experience" and derived without a detailed understanding of the cost base. Both our intervention in the negotiation process with our detailed cost analysis, and this later transparency exercise, contributed greatly to later understanding.

Transparency provided specific benefits for principals and agents alike. For principals, it allowed problems of adverse selection to be identified. Calculations showed this to be most significant in southern Norway, where population densities were relatively high and transport distances relatively short. Our observations suggested it was relatively easy for agents to run a profitable transport business in this part of the country (especially if adverse-selecting) but that agents were not as lean and efficient in their operations as they could have been. Transparency allowed principals to identify adverse selection and drive down costs, whereas agents identified cost savings and efficiency gains to remain profitable. In northern Norway, with longer transport distances and lower volumes owing to sparse population, operating a profitable WEEE transport business is considerably more difficult. Here, transparency and engagement with the costing model allowed agents to understand how keeping vehicles on the road was vital for driving down costs; savings of $30 \%+$ on very high initial unit costs were possible through effective vehicle utilisation [4]. Overall, the transparency exercise led to an immediate total cost (price) reduction across all activities of around $22 \%$, corresponding to around 15 million Norwegian kroner (nearly \$2M) per year. A further $10 \%$ reduction was achieved the following year (private communication).

The interventions have resulted in a considerably more open and transparent dialogue between principals and (potential) agents throughout the contractual process. As outlined above, we initiated a post-contractual "transparency process" involving populating the costing model with detailed data-this continues to this day, without external intervention, as part of the normal contractual re-negotiation process. We are informed by the parties concerned that subsequent iterations of the transparency process have become progressively easier and more streamlined as all parties become both comfortable with the process and more knowledgeable regarding the underlying data. What was clear at the time was that the interplay between different cost drivers (fixed, variable and salary costs) was far from clear in the absence of in-depth analysis. Improving such analysis with the best information available depends on transparent co-operation between the parties. This enables a clear focus on the cost drivers which matter most, with benefits for both supplier and purchaser.

\section{Conclusions}

The study reveals several key themes. Firstly, almost all the highlighted difficulties stem from the negotiation and contract-making process, in accord with a "battle and truce" model. We have already suggested that there is a potential alternative based on a drive for collaboration and mutual benefit. We have described various contractual and pricing structures in theory. In practice it seems inevitable that outcome-based contracts (priced per unit mass) will remain the norm-but perhaps with behavioural-based options, clauses or caveats. Most importantly, all the analysis thus far highlights the importance of information in contractual matters, the dangers of incomplete and asymmetric information and the need for transparency and information-sharing in transport negotiation. As noted previously [5], there is a tendency for some cost drivers-such as the cost of fuel-to be in strong focus, probably because of their obviousness, measurability or visibility, more than their true importance.

In addition to transparency between PROs and carriers, there is also plenty of evidence to support greater transparency in the relationships between PROs where they are in competition with each other. A comparative study of WEEE EPR systems across the Nordic region [32] suggested that the Danish approach of centrally allocating specific collection points to PROs may be preferable to PROs effectively competing for collection points, as in Sweden and especially in Norway. This could lead to considerable efficiency savings but would depend crucially on PROs engaging in highly transparent and open dialogue, both with each other and with moderating third parties, to ensure a fair allocation for all parties. 
The broad effect of our interventions was to better inform all parties regarding the true costs, to render the contractual interactions much more collaborative and to greatly reduce principal-agent problems such as adverse selection. Fostering an atmosphere of transparency was the principal mechanism for these improvements. Proper mutual understanding of the cost base is of considerable potential benefit to all. It offers the possibility of effectively benchmarking current activity, and of assessing the potential effects of changes on a systematic basis. Previous work [4] presents this in some detail for the Norwegian WEEE value chain. Understanding the effect of change opens the door to focused investment and innovation, where one can be fairly sure of the precise implications for bottom-line cost. More generally, understanding the cost base can ultimately make costing and pricing more reflective of the true difficulty and onerousness of WEEE transport. In this sense, there is a strong parallel with earlier work on treatment and recycling, where the lack of such a link between price and true operational difficulty/cost has been identified as a major shortcoming [12].

The various parties' engagement in a collaborative research effort meant that relative goodwill and willingness to share business-confidential information was stronger here than might be expected in general. External facilitation of transparency processes, coupled with concentrated effort in promoting the likely benefits to principals and agents alike, is probably essential. This will likely be increasingly challenging in more adversarial business environments.

A more transparent, collaborative relationship between PROs and carriers could also facilitate outreach to other stakeholders, particularly the waste-holders, with a view to further raising efficiency and driving down costs. Inefficient waste collections stem to some degree from demand patterns. Waste-holders could conceivably be encouraged to modify their demand patterns-perhaps lowering the frequency of demand or increasing the acceptable lead-time between demand and actual collection. This could allow carriers to, for example, improve planning and to collect full vehicle loads as quickly as possible with minimal intermediate driven distance. The work suggests that certain waste-holders could be provided with specific incentives to act in this fashion. This would imply some significant changes to the EPR system (waste-holders are effectively proxy representatives of electronics producers, and do not have specific contractual arrangements with PROs) but is possible in principle. More generally, a more transparent and collaborative atmosphere than is often typical for relationships right along the WEEE value chain can lead to significant efficiency, and ultimately environmental, benefits.

Author Contributions: Both authors contributed equally to all parts of the study and preparation of the article. All authors have read and agreed to the published version of the manuscript.

Funding: This work was supported by the SmartEEre-Returtransport project within the SMARTRANS programme of the Norwegian Research Council (Norges Forskningsrådet) [Grant Number 227083].

Conflicts of Interest: The authors declare no conflict of interest.

\section{References}

1. Oslo Kommune Bryter Kontrakten Med Veireno-Kommunen Tar over Ansvaret for Renovasjonen [Oslo Municipality Breaks Its Contract with Veireno-Takes over Responsibility for Collection]. [In Norwegian]. Available online: https://www.dagbladet.no/nyheter/oslo-kommune-bryter-kontrakten-med-veireno--kommunen-tar-over-ansvaret-for-renovasjonen/67195404 (accessed on 8 March 2020).

2. Fakta om RenoNorden-Konkursen [Facts about the RenoNorden Bankruptcy]. [In Norwegian]. Available online: https://www.dagbladet.no/nyheter/soppelkonkurs-ga-stopp-for-private/69898819 (accessed on 8 March 2020).

3. Nilssen, J.E.; Sylthe, M.; Testa, G.; Bakken, B.E. Time calculation of waste collection routes: Case study from the City of Oslo. Waste Manag. Res. 2019, 37, 667-673. [CrossRef] [PubMed]

4. Bø, E.; Baxter, J. The effects of geographical, operational and service parameters on WEEE transport networks. Int. J. Logist. Res. Appl. 2017, 20, 342-358. [CrossRef]

5. Bø, E.; Hammervoll, T. Cost-based pricing of transportation services in a wholesaler-carrier relationship: An MS Excel spreadsheet decision tool. Int. J. Logist. Res. Appl. 2010, 13, 197-210. [CrossRef] 
6. Bing, X.; Bloemhof, J.M.; Ramos, T.R.P.; Barbosa-Povoa, A.P.; Wong, C.Y.; van der Vorst, J.G. Research challenges in municipal solid waste logistics management. Waste Manag. 2016, 48, 584-592. [CrossRef] [PubMed]

7. Islam, M.T.; Huda, N. Reverse logistics and closed-loop supply chain of Waste Electrical and Electronic Equipment (WEEE)/E-waste: A comprehensive literature review. Resour. Conserv. Recycl. 2018, 137, 48-75. [CrossRef]

8. Gomes, M.I.; Barbosa-Povoa, A.P.; Novais, A.Q. Modelling a recovery network for WEEE: A case study in Portugal. Waste Manag. 2011, 31, 1645-1660. [CrossRef]

9. Aras, N.; Korugan, A.; Büyüközkan, G.; Şerifoğlu, F.S.; Erol, İ.; Velioğlu, M.N. Locating recycling facilities for IT-based electronic waste in Turkey. J. Cleaner. Prod. 2015, 105, 324-336. [CrossRef]

10. Kilic, H.S.; Cebeci, U.; Ayhan, M.B. Reverse logistics system design for the waste of electrical and electronic equipment (WEEE) in Turkey. Resour. Conserv. Recycl. 2015, 95, 120-132. [CrossRef]

11. Gamberini, R.; Gebennini, E.; Manzini, R.; Ziveri, A. On the integration of planning and environmental impact assessment for a WEEE transportation network-A case study. Resour. Conserv. Recycl. 2010, 54, 937-951. [CrossRef]

12. Mayers, K.; Lifset, R.; Bodenhoefer, K.; Wassenhove, L.N. Implementing Individual Producer Responsibility for Waste Electrical and Electronic Equipment through Improved Financing. J. Ind. Ecol. 2013, 17, 186-198. [CrossRef]

13. Hammervoll, T.; Bø, E. Shipper-carrier integration Overcoming the transparency problem through trust and collaboration. Eur. J. Mark. 2010, 44, 1121-1139. [CrossRef]

14. Fawcett, S.E.; Magnan, G.M. The rhetoric and reality of supply chain integration. Int. J. Phys. Distrib. Logist. Manag. 2002, 32, 339-361. [CrossRef]

15. Hoyt, J.; Huq, F. From arms-length to collaborative relationships in the supply chain; An evolutionary process. Int. J. Phys. Distrib. Logist. Manag. 2000, 30, 750-764. [CrossRef]

16. Simatupang, T.M.; Sridharan, R. The collaborative supply chain. Int. J. Logist. Manag. 2002, 13, 15-30. [CrossRef]

17. Christopher, M. Logistics E Supply Chain Management, 5th ed.; Pearson Higher Ed: New York, NY, USA, 2016.

18. Baudin, M. Lean Logistics: The Nuts and Bolts of Delivering Materials and Goods; Productivity Press: New York, NY, USA, 2004.

19. Baxter, J.; Wahlstrom, M.; Zu Castell-Rüdenhausen, M.; Fråne, A.; Stare, M.; Løkke, S.; Pizzol, M. Plastic Value Chains: Case: WEEE (Waste Electric and Electronic Equipment) in the Nordic Region; Nordic Council of Ministers: Copenhagen, Denmark, 2014.

20. Eisenhardt, K.M. Agency theory: An assessment and review. Acad. Mgt. Rev. 1989, 14, 57-74. [CrossRef]

21. Sajad, F.; Andrew, O.L.; Ambika, Z. Agency theory and supply chain management: A structured literature review. Supply Chain Manag. Int. J. 2012, 17, 556-570.

22. Logan, M. Using Agency Theory to Design Successful Outsourcing Relationships. Int. J. Logist. Manag. 2000, 11, 21-32. [CrossRef]

23. Bergen, M.; Dutta, S.; Walker, O.C., Jr. Agency relationships in marketing: A review of the implications and applications of agency and related theories. J. Mark. 1992, 56, 1. [CrossRef]

24. Reason, P.; Bradbury, H. (Eds.) Handbook of Action Research: Participative Inquiry and Practice; Sage: London, UK, 2001.

25. Näslund, D. Logistics needs qualitative research-Especially action research. Int. J. Phys. Distrib. Logist. Manag. 2002, 32, 321-338. [CrossRef]

26. Romsdal, A. The appropriateness of action research to achieve increased supply chain sustainability-A case study. In Proceedings of the Francesco Turco Summer School, Porto Giardino, Italy, 15-19 September 2009.

27. Fagundes, L.D.; Amorim, E.S.; Lima, R. Action research in reverse logistics for end-of-life tire recycling. Syst. Pract. Action Res. 2017, 30, 553-568. [CrossRef]

28. Bradbury-Huang, H. Editorial. Action Res. 2012, 10, 111-114. [CrossRef]

29. Eady, S.; Drew, V.; Smith, A. Doing action research in organizations: Using communicative spaces to facilitate (transformative) professional learning. Action Res. 2015, 13, 105-122. [CrossRef]

30. Susman, G.I.; Evered, R.D. An Assessment of the Scientific Merits of Action Research. Adm. Sci. Q. 1978, 23, 582-603. [CrossRef] 
31. Karlsen, G.-A.; Aanestad, H.O. A Case Study of Costs and Influencing Factors for WEEE-collection in Oslo. Master's Thesis, BI Norwegian Business School, Oslo, Norway, 2015.

32. Kjellsdotter, L.; Raadal, H.L.; Fråne, A.; Ljungkvist, H. The Role of the WEEE Collection and Recycling System Setup on Environmental, Economic and Socio-Economic Performance-IVL; Swedish Environmental Research Institute: Gothenburg, Sweden, 2015.

(C) 2020 by the authors. Licensee MDPI, Basel, Switzerland. This article is an open access article distributed under the terms and conditions of the Creative Commons Attribution (CC BY) license (http://creativecommons.org/licenses/by/4.0/). 